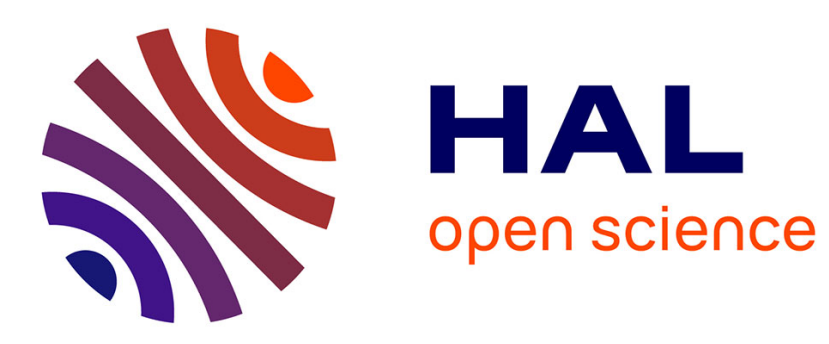

\title{
Structural vibrations induced by HVI - application to the Gaïa spacecraft
}

J.B. Vergniaudm.Guyot, M. Lambert, F. Schafer, S. Ryan, S. Hiermaier, E. Taylor

\section{- To cite this version:}

J.B. Vergniaudm.Guyot, M. Lambert, F. Schafer, S. Ryan, S. Hiermaier, et al.. Structural vibrations induced by HVI - application to the Gaïa spacecraft. International Journal of Impact Engineering, 2008, 35 (12), pp.1836. 10.1016/j.ijimpeng.2008.07.029 . hal-00542563

HAL Id: hal-00542563

https://hal.science/hal-00542563

Submitted on 3 Dec 2010

HAL is a multi-disciplinary open access archive for the deposit and dissemination of scientific research documents, whether they are published or not. The documents may come from teaching and research institutions in France or abroad, or from public or private research centers.
L'archive ouverte pluridisciplinaire HAL, est destinée au dépôt et à la diffusion de documents scientifiques de niveau recherche, publiés ou non, émanant des établissements d'enseignement et de recherche français ou étrangers, des laboratoires publics ou privés. 


\section{Accepted Manuscript}

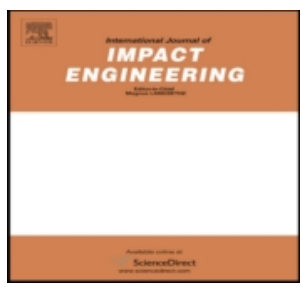

Title: Structural vibrations induced by HVI - application to the Gaïa spacecraft

Authors: J.B. VergniaudM.Guyot, M. Lambert, F. Schafer, S. Ryan, S. Hiermaier, E. Taylor

PII: $\quad$ S0734-743X(08)00146-2

DOI: $\quad$ 10.1016/j.ijimpeng.2008.07.029

Reference: IE 1628

To appear in: International Journal of Impact Engineering

Received Date:

Revised Date:

Accepted Date:

Please cite this article as: VergniaudM.Guyot JB, Lambert M, Schafer F, Ryan S, Hiermaier S, Taylor E. Structural vibrations induced by HVI - application to the Gaïa spacecraft, International Journal of Impact Engineering (2008), doi: 10.1016/j.ijimpeng.2008.07.029

This is a PDF file of an unedited manuscript that has been accepted for publication. As a service to our customers we are providing this early version of the manuscript. The manuscript will undergo copyediting, typesetting, and review of the resulting proof before it is published in its final form. Please note that during the production process errors may be discovered which could affect the content, and all legal disclaimers that apply to the journal pertain. 


\title{
Structural vibrations induced by HVI - application to the Gaïa spacecraft
}

\author{
J.B. Vergniaud ${ }^{*}$, M.Guyot ${ }^{1}$, M. Lambert ${ }^{2}$, \\ F. Schafer ${ }^{3}$, S. Ryan 3 , S. Hiermaier ${ }^{3}$, E. Taylor ${ }^{4}$ \\ (1) EADS Astrium, 31 rue des Cosmonautes, 31402 Toulouse Cedex 4, France \\ (2) ESA - ESTEC, Keplerlaan 1 Postbus 299, NL-2200 AG Noordwijk, The Netherlands \\ (3) Fraunhofer-Institute for High-Speed Dynamics EMI, Eckerstr. 4, D- 79104 Freiburg, Germany \\ (4) The Open University, Walton Hall, Milton Keynes, MK7 6AA, United Kingdom
}

\begin{abstract}
Given the growing stability needed for spacecraft in operation to ensure functioning of future instruments whose sensitivity requires an important technological step, perturbations encounter in orbital conditions that used to be negligible, become today an issue. This is the case of micrometeorite impacts whose energy could induce modal response of the flexible structure and imply a dynamic response of the spacecraft which could probably be disturbing for the instrument functioning. The impact environment that could be encountered by the spacecraft is preliminary studied before the definition of test to recreate the excitation with light-gas gun. Experiments are made on samples of structure representative of the ongoing Gaia astrometric mission project. Response of the structure is recorded to be correlated to finite elements model of the sample. The excitation is then extrapolated to orbital conditions and to Gaïa finite elements model. The final perturbation is compared to the specification. The main conclusion is that for daily impact event, dynamic response of the structure will not disturb Gaïa functioning. Nevertheless, for a yearly impact event, the astrometric mission will largely be disturbed by the dynamic response of the structure to the impact.
\end{abstract}

Keywords: Hyper velocity impact, Structural dynamic response, modal response, Shock Response Spectra, Gaïa

\section{Introduction}

Some of the future scientific missions to be launched in the next decade represent an important technological step forward due to the high measurement accuracy which is aimed. As a consequence, requirements in terms of payload environment stability are much more severe than in the past. The pointing stability requirements for Gaïa spacecraft mission (developed for European Space Agency) are orders of magnitude lower than for typical missions currently developed. In such a case, disturbances

*Corresponding author. Tel.: +33 (0)56219-6874; fax: +33 (0)56279-7744.

E-mail address: jean-baptiste.vergniaud@astrium.eads.net 
induced by micrometeoroids impacts can not been neglected. To evaluate the corresponding risk, induced perturbations in the vicinity of the sensitive equipment shall be characterized.

The effect of hypervelocity impacts on spacecrafts is usually tackled in two different ways. The first way considers micro particle impacts induced on the structure which is mainly an issue for manned flights where safety considerations play an important role in the spacecraft design and conception. Damages inflicted by hypervelocity impacts can significantly decrease life expectation of unmanned flights, which is a commercial issue as the spacecraft has been sold for a given life duration. In both cases, hypervelocity impacts deal mainly with strength of materials (see [1] and [2]).

The other common way considers in flight impacts in terms of momentum transfer that may affect spacecraft trajectory. The energy brought by the impacts provides axial and angular momentum depending on the impact direction and location with respect to the spacecraft orbit and centre on gravity. Such perturbations have to be counterbalanced by altitude control reaction to keep the initial trajectory. In this case, the effect of impact mainly deals with altitude control where spacecraft is basically considered as a nonflexible solid and is mainly linked to the performance of the system with respect to a given specification.

Ongoing projects have emphasized the important issue of in-flight structural dynamic stability to ensure the aimed accuracy (see [7]). Considering the spacecraft as a nonflexible structure only is not sufficient to predict its stability. The dynamic behavior of the structure gets superimposed to the rigid body movement and disturbs the functioning of the system if it is stimulated. The dynamics of the spacecraft is essentially stimulated according to the following viewpoints:

- Internal spacecraft rotating mechanism (such as positioning wheels) maintain the excitation of modal content of the structure.

- The dynamical response to the shock loading induced by hypervelocity impacts which are part of the overall external spacecraft environment provides a source of excitation which could disturb the spacecraft stability.

The main objective of this study is precisely to estimate the influence of hypervelocity impacts on the dynamical response of the spacecraft in order to assess the effect of this type of excitation on its inflight performance. The structure of this article reflects the process which has been followed for this study. The objective was twofold:

- Provide realistic measurements of hypervelocity impact effect on spacecraft dynamical response.

- Assess the possibility to model with reasonable confidence the consequences of impacts on an industrial sensitive project by extrapolating the measured environment.

Consequently, a preliminary study of orbital impact flux and representative impacted target will be presented. Then, the test campaigns reproduce the hypervelocity impact environment on selected targets will be described. Finally, modeling aspect will be tackled first to simulate test conditions on impacted targets and then to extrapolate in-flight conditions for the Gaïa astrometric mission.

\begin{tabular}{|ll|}
\hline Nomenclature & \\
FEM & Finite Elements Model \\
HC & Honeycomb \\
HVI & Hyper velocity impact \\
LOS & Line Of Sight \\
\hline
\end{tabular}


Vergniaud, et al / International Journal of Impact Engineering

\begin{tabular}{|ll|}
\hline mas & milli-arc-second \\
Mas & micro-arc-second \\
PLM & Payload module \\
SRS & Shock Response Spectra \\
SVM & Service Module \\
SW & Sandwich panel \\
\hline
\end{tabular}

\section{Review of the Gaia Spacecraft Configuration}

A review of the Gaïa spacecraft configuration has been led in order to define targets representative of the spacecraft structure, and to identify relevant micrometeoroid impact conditions to be faced by the spacecraft in orbit.

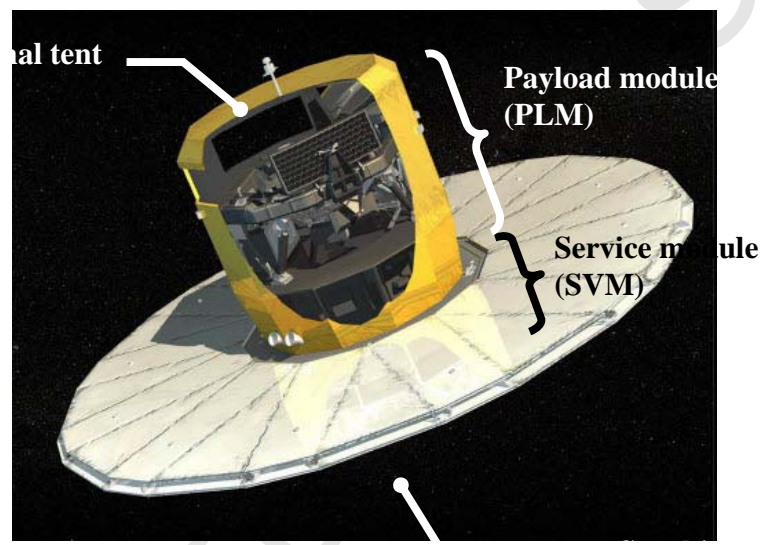

Fig. 1. View of the overall Gaïa spacecratt configuration

\subsection{Representative Targets}

The detailed review of the Gaïa spacecraft design has shown that the external walls are made of sandwich panels with CFRP (Carbon Fiber Reinforced Plastics) skins and aluminum honeycomb. The CFRP skin thickness is typically 0.5 or $0.6 \mathrm{~mm}$ and the aluminum honeycomb thickness lies between 10 and $50 \mathrm{~mm}$. Therefore the main part of the targets defined for the HVI tests are CFRP sandwich panels representative of the Gaïa external walls both in terms of material and configuration. In addition, to experimentally assess the influence of the sandwich panel design, targets with various skin and honeycomb thicknesses have been manufactured. Gaïa external walls are covered either by MLI or solar cells. Bare walls are never used. There is a need to characterize the influence of MLI and of solar cells, as it can change dramatically the impact physics and therefore the elastic energy transmitted to the structure. For this reason, additional targets have been defined including MLI and solar cells to be able to compare the induced vibrations with respect to a bare target, as shown in Fig. 2. 
Bulk

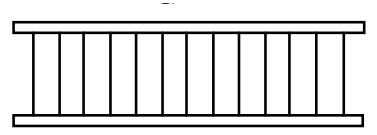

MLI

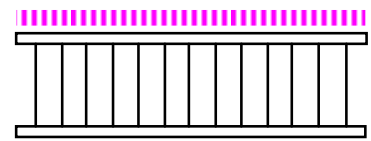

Solar cells

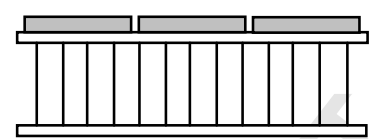

Fig. 2. Targets have been defined to assess the influence of MLI and solar cells

For classical shock wave propagation, the attenuation along a given structural path mainly comes from interfaces. Therefore typical interfaces have been identified on the Gaïa spacecraft configuration, leading to the definition of panel assemblies to be tested in the frame of this HVI test campaign. These additional targets are made of CFRP sandwich panels assembled thanks to aluminum brackets, as shown on Fig. 3.

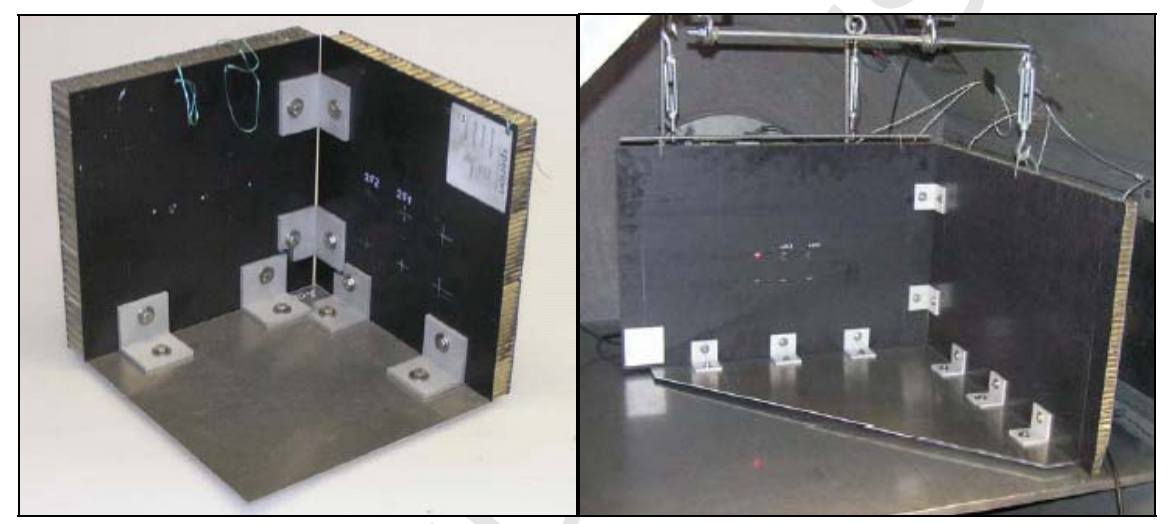

Fig. 3. Assemblies have been tested to characterize the attenuation through interfaces

In addition to the targets representative of the Gaïa configuration, aluminum and CFRP plates have been tested in order to characterize some reference configurations. This is used as a first step to validate the ability of our simulation codes to predict the vibrations induced by the HVI.

\subsection{Relevant Impact Conditions}

A flux analysis has been performed on Gaïa in order to identify the micrometeoroid impact conditions relevant for the present study (see [5] and [6]). The Gaïa spacecraft is located at the Lagrangian point L2, its attitude (spinning with a precession of its spin axis) means that spacecraft's time averaged exposure to the meteoroid environment is essentially isotropic. The interplanetary meteoroid flux (IMF) distribution has been used in combination with a revised Harvard Radio Meteor Project (HRMP) meteoroid velocity distribution and led to the following fluxes for the various Gaïa parts as shown in Table 1.

From the spacecraft point of view, hypervelocity impacts can be classified into several groups depending on their criticality for the mission: 
Vergniaud, et al / International Journal of Impact Engineering

- Low level but frequent impacts leading to a "noise-like" dynamic disturbance. As a consequence, even if the disturbance level is very low, this could continuously degrade the accuracy of the scientific data. This type of impact concerns particles with an impact frequency higher than one impact per hour.

Table 1. Results of the micrometeoroid flux analysis performed on Gaïa

\begin{tabular}{cccccccc}
\hline & \multicolumn{7}{c}{ Micrometeoroid differential fluxes (per year) } \\
\cline { 2 - 8 } $\begin{array}{c}\text { Log mass } \\
\text { range }(\mathrm{kg})\end{array}$ & $\begin{array}{c}\text { SVM SA } \\
\text { (bottom) }\end{array}$ & SVM lateral & $\begin{array}{c}\text { Focal plane } \\
\text { radiator }\end{array}$ & PLM tent & $\begin{array}{c}\text { PLM tent } \\
\text { roof }\end{array}$ & Sunshield & Total \\
\hline-15 to -14 & $5.99 \mathrm{E}+03$ & $2.84 \mathrm{E}+03$ & $6.60 \mathrm{E}+02$ & $8.47 \mathrm{E}+03$ & $3.97 \mathrm{E}+03$ & $9.09 \mathrm{E}+04$ & $\mathbf{1 . 1 3 E}+\mathbf{0 5}$ \\
-14 to -13 & $2.61 \mathrm{E}+03$ & $1.24 \mathrm{E}+03$ & $2.88 \mathrm{E}+02$ & $3.69 \mathrm{E}+03$ & $1.73 \mathrm{E}+03$ & $3.96 \mathrm{E}+04$ & $\mathbf{4 . 9 2 E + 0 4}$ \\
-13 to -12 & $1.04 \mathrm{E}+03$ & $4.92 \mathrm{E}+02$ & $1.14 \mathrm{E}+02$ & $1.47 \mathrm{E}+03$ & $6.88 \mathrm{E}+02$ & $1.58 \mathrm{E}+04$ & $\mathbf{1 . 9 6 E}+\mathbf{0 4}$ \\
-12 to -11 & $5.60 \mathrm{E}+02$ & $2.65 \mathrm{E}+02$ & $6.17 \mathrm{E}+01$ & $7.92 \mathrm{E}+02$ & $3.71 \mathrm{E}+02$ & $8.50 \mathrm{E}+03$ & $\mathbf{1 . 0 5 E}+\mathbf{0 4}$ \\
-11 to -10 & $2.70 \mathrm{E}+02$ & $1.28 \mathrm{E}+02$ & $2.97 \mathrm{E}+01$ & $3.81 \mathrm{E}+02$ & $1.79 \mathrm{E}+02$ & $4.10 \mathrm{E}+03$ & $\mathbf{5 . 0 9 E}+\mathbf{0 3}$ \\
-10 to -9 & $7.81 \mathrm{E}+01$ & $3.70 \mathrm{E}+01$ & $8.60 \mathrm{E}+00$ & $1.10 \mathrm{E}+02$ & $5.17 \mathrm{E}+01$ & $1.18 \mathrm{E}+03$ & $\mathbf{1 . 4 7 E}+\mathbf{0 3}$ \\
-9 to -8 & $1.30 \mathrm{E}+01$ & $6.16 \mathrm{E}+00$ & $1.43 \mathrm{E}+00$ & $1.84 \mathrm{E}+01$ & $8.62 \mathrm{E}+00$ & $1.97 \mathrm{E}+02$ & $\mathbf{2 . 4 5 E}+\mathbf{0 2}$ \\
-8 to -7 & $1.32 \mathrm{E}+00$ & $6.25 \mathrm{E}-01$ & $1.45 \mathrm{E}-01$ & $1.87 \mathrm{E}+00$ & $8.75 \mathrm{E}-01$ & $2.00 \mathrm{E}+01$ & $\mathbf{2 . 4 8 E}+\mathbf{0 1}$ \\
-7 to -6 & $9.46 \mathrm{E}-02$ & $4.48 \mathrm{E}-02$ & $1.04 \mathrm{E}-02$ & $1.34 \mathrm{E}-01$ & $6.27 \mathrm{E}-02$ & $1.43 \mathrm{E}+00$ & $\mathbf{1 . 7 8 E + 0 0}$ \\
-6 to -5 & $1.47 \mathrm{E}-03$ & $6.94 \mathrm{E}-04$ & $1.62 \mathrm{E}-04$ & $2.07 \mathrm{E}-03$ & $9.71 \mathrm{E}-04$ & $2.22 \mathrm{E}-02$ & $\mathbf{2 . 7 6 E}-\mathbf{0 2}$ \\
\hline
\end{tabular}

- Intermediate level and less frequent impacts, which can be considered as discrete events. These impacts lead to a temporary loss of the scientific data, due to a disturbance level relatively high when compared to the equipment accuracy. This concerns particles with an impact frequency between 1 impact per day and 1 impact per month.

- Rare but high level impacts. Such particles lead at least to a temporary loss of the spacecraft attitude. These particles have an impact probability lower than 1 impact per year. This type of impacts is out of the scope of the present study, which focuses more on micro-vibration aspects.

As a consequence, the typical in orbit impact conditions taken into account are those corresponding to a flux between 1 impact per hour and 1 impact per month. Thus, the relevant in orbit impact conditions for Gaïa are a micrometeoroid mass between $10^{-7} \mathrm{~kg}$ and $10^{-11} \mathrm{~kg}$, and a velocity ranging from 11 to $72 \mathrm{~km} / \mathrm{s}$.

\section{Test Description and Data Analysis}

The primary objectives of the main impact test campaign are the investigation of impact-induced wave propagation in simple and complex structures and their vibrations during long times after the impact event. Test configuration is inspired by previous preliminary measurement of vibration HVI induced in CNES and CEG study (see [3]). The wave propagation data are used primarily for validation of hydrocode impact simulations in view of generating the excitation function. The vibration data are exploited primarily for comparison against FEM predictions of the impact-induced vibrations in structures. 
Vergniaud, et al / International Journal of Impact Engineering

\subsection{Test Description}

\subsubsection{Test facilities}

Tests are performed with 2-stage light gas guns. Test facilities and light gas gun operation are described in [4]. The targets are settled at the end of the launch tube in a vacuum chamber where it is hold in place with very low frequency boundary conditions (to be as close as possible to the orbital mechanical free-free conditions).

Vibratory environment induced on different tested structure is recorded thanks to both Kistler and Endevco acceleration sensors. These to types of sensor allow having a large spectrum of sensitivity and resonance in order to emphasize large frequency and level ranges phenomena. On single panels, two accelerometers are set up. Five accelerometers are set up for assemblies. A laser Vibrometer is also available to measure the velocity response of the structure close to the impact point. This measurement is helpful for determining the equivalent force induced at the impact location (see Fig. 4. ).

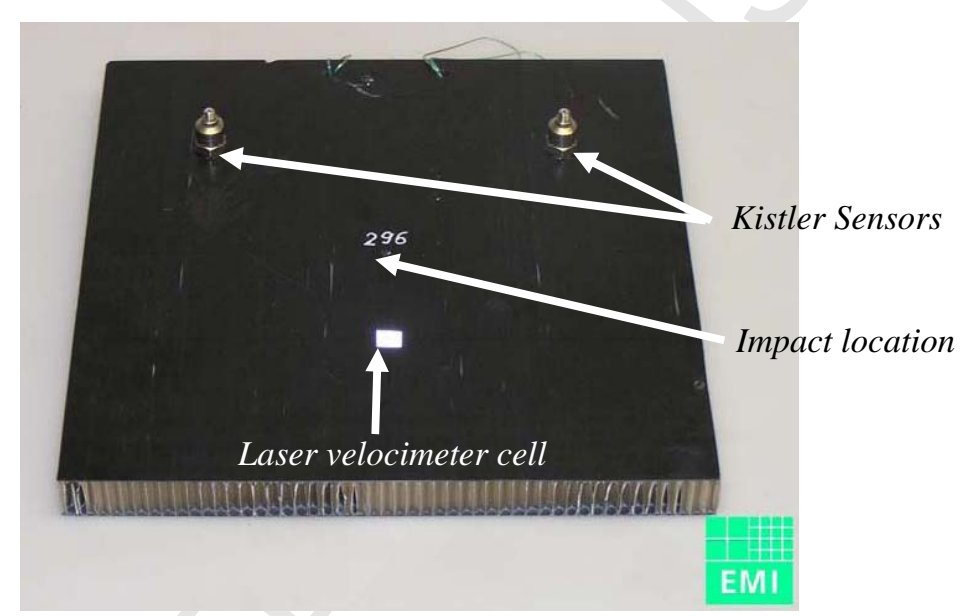

Fig. 4. Instrumentation illustration on impacted targets

\subsubsection{Impact conditions}

The ideal testing impact conditions would be to launch particles with a size which is largely smaller and faster than what is today possible to launch with the available technology. The smaller are the particles for a given launch velocity the harder it is to control the travel of the projectile in the launch tube. To solve these difficulties, a sabot is used to keep the particle along the tube axis. The range of impact conditions which are used for this study varies between $0.8 \mathrm{~mm}$ and $1.5 \mathrm{~mm}$. The launching speed goes from $3.5 \mathrm{~km} / \mathrm{s}$ to $7 \mathrm{~km} / \mathrm{s}$ and the incidence at impact is normal to the target front face. Due to the limited number of targets, all of them sustain multiple impact events, which means that targets are not necessarily impacted at the same location. The synthesis of test matrix followed during the test campaign is presented in Table 2. The effects of impacts on targets are illustrated on 0 
Vergniaud, et al / International Journal of Impact Engineering

Table 2. Synthesis of test matrix

\begin{tabular}{|c|c|c|c|c|c|c|}
\hline \multirow{2}{*}{ Target type } & \multirow{2}{*}{$\begin{array}{c}\text { Number of } \\
\text { targets tested }\end{array}$} & \multirow{2}{*}{$\begin{array}{l}\text { Number } \\
\text { of tests }\end{array}$} & \multirow{2}{*}{ Size } & \multirow{2}{*}{ Materials } & \multicolumn{2}{|c|}{ Impact condictions range } \\
\hline & & & & & Velocity & Particle size \\
\hline $\begin{array}{l}\text { Small single } \\
\text { targets }\end{array}$ & 6 & 12 & $250 \times 250 \mathrm{~mm}$ & $\begin{array}{c}\text { Aluminium }(1-2 \mathrm{~mm}), \mathrm{SW} \text { panel } \\
\text { (Skin CFRP 0.5-1mm - HC } \\
\text { Aluminium 20-30mm), CFRP } \\
\text { plate }\end{array}$ & $\begin{array}{l}3.4 \mathrm{~km} / \mathrm{s}- \\
5.7 \mathrm{~km} / \mathrm{s}\end{array}$ & $0.8 \mathrm{~mm}-1.5 \mathrm{~mm}$ \\
\hline $\begin{array}{l}\text { Large single } \\
\text { targets }\end{array}$ & 2 & 6 & $600 \times 400 \mathrm{~mm}$ & $\begin{array}{c}\text { Aluminium }(2 \mathrm{~mm}), \mathrm{SW} \text { panel } \\
\text { (Skin CFRP 0.5mm - HC } \\
\text { Aluminium 20mm) }\end{array}$ & $\begin{array}{l}5.3 \mathrm{~km} / \mathrm{s}- \\
6.8 \mathrm{~km} / \mathrm{s}\end{array}$ & $1.5 \mathrm{~mm}$ \\
\hline $\begin{array}{c}\text { Small } \\
\text { aseemblies }\end{array}$ & 6 & 9 & $250 \times 250 \times 250 \mathrm{~mm}$ & $\begin{array}{c}\text { Aluminium (1-2mm), SW panel } \\
\text { (Skin CFRP 0.5-1mm - HC } \\
\text { Aluminium 20-30mm) }\end{array}$ & $\begin{array}{l}3.5 \mathrm{~km} / \mathrm{s}- \\
5.2 \mathrm{~km} / \mathrm{s}\end{array}$ & $0.8 \mathrm{~mm}-1.5 \mathrm{~mm}$ \\
\hline $\begin{array}{c}\text { Large } \\
\text { assemblies }\end{array}$ & 2 & 4 & $600 \times 400 \times 600 \mathrm{~mm}$ & $\begin{array}{c}\text { Aluminium (2mm), SW panel } \\
\text { (Skin CFRP 0.5mm - HC } \\
\text { Aluminium 20mm) }\end{array}$ & $\begin{array}{l}4.5 \mathrm{~km} / \mathrm{s}- \\
6.5 \mathrm{~km} / \mathrm{s}\end{array}$ & $1.5 \mathrm{~mm}$ \\
\hline Total & 16 & 31 & & & & \\
\hline
\end{tabular}
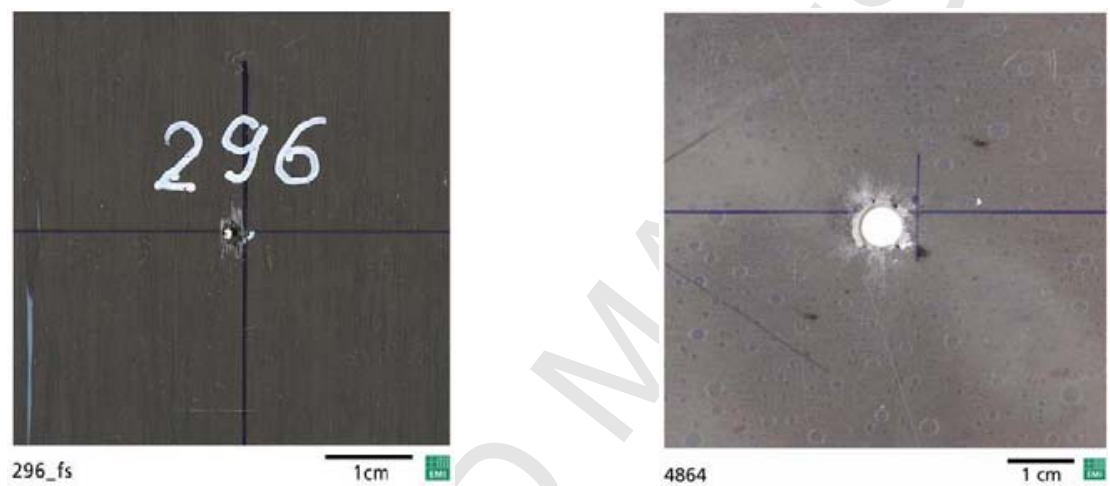

Fig. 5. Impact holes on different targets (a) SW panels - Impact effects (b) Aluminum panels - Impact effects

\subsection{Test Set-Up Validation}

Test set-up is validated to ensure the fact that the environment measured during tests on selected targets is precisely the dynamic response of the undisturbed structure. However, two major sources of perturbation have been identified. The first one is the mechanical shock and vibration transmitted to the whole impact facility including the impact chamber mainly induced by the ignition and combustion of the gun powder, the encounter of the sabot parts with the sabot catcher, and the interaction (i.e. encounter) of the blast wave with the facilities' tank walls. The second source of perturbations comes form the direct blast pressure effect induced by the hot hydrogen gas that is expelled into the blast tank and burns as it mixes with the residual oxygen contained in it.

\subsection{Test Data Analysis}

The synthesis of the analysis of the HVI test results examines the coherence between the different tests, which allows a rich analysis of the differences between tests of phase one and two. The influence of parameters is also studied. 
Vergniaud, et al / International Journal of Impact Engineering

The materials: the most important effect is the local stiffness of the impacted part of the target. The multiplication by two the skin thickness generates level ten times higher on the first modal response, whereas the thickness of Honeycomb has a reduced influence (except on the overall thickness of the target, which means the frequency of its modes). This explains why impacts on aluminum target are difficult to analyze given very high levels induced.

The projectile property has a second order influence: the size and the velocity play as squared on first mode response (proportionality with the area impacted and with kinetic energy). Results do not allow being more precise. More tests are needed to determine the precise law governing these parameters, especially by using more important velocity range for more comparable tests.

The covering of the target provide an absorbing effect by keeping a part of the projectile energy which implies a reduction of levels induced on the low frequency modal response. This is particularly the case for solar cells whereas MLI covering has about no influence. The effect of covering mass can also lead to frequency shift which has been observed for solar cells influence.

HVI implies an excitation of the first overall modes of the different assemblies which leads to vibratory perturbation of the spacecraft. This excitation of low frequency modal content highly disturbs its performance in terms of instruments line of sight. The various interfaces lead to both damp high frequency content (which confirms the need to concentrate on low frequency domain) and level the effect of the impact wherever it occurs.

Marble drop impact (performed prior to HVI) can be considered as a first approach to recreate with a non destructive experiment the effect of HVI on a structure. Excluding the influence of local stiffness, the conclusions drawn from such experiment are the same as for HVI tests. But the effect of the impact does not allow creating the specific response of an HVI which implies a different distribution of excitation in the frequency domain.

\section{Simulations}

\subsection{Objectives of Simulations}

The main objective is to apply the modeled excitation induced by the impact on actual Gaïa spacecraft structure in order to get a preliminary approach of the consequence of this type of excitation The use of dedicated software to treat the problem might be time and resource consuming as no specific model of the spacecraft exists in the correct format. The model is dedicated to NASTRAN software. Consequently, for availability reasons, the study will be conducted with the help of NASTRAN software to simulate levels of response induced by impacts. The model specifications are the following:

- The elements used for target modeling are typical elements representative of satellite system model used, for instance, in satellite micro vibration analysis. The structural part is modeled with two dimensional shell elements (CQUAD, CTRIA). Substructures are linked to each other with dedicated and typical bounding elements.

- Size of elements is representative of common model. It has been emphasized that the excitation induced by impacts is usually consistent with high frequency content at the source point. Mesh size is probably the most limiting factor for the high frequency representation of impact consequences across the structure. But as said earlier, interfaces between sub-structures will dampen the highest content and only the most disturbing frequencies will remain.

- The excitation is introduced in the model as an effort. Given the projectiles size (less than $2 \mathrm{~mm}$ 
Vergniaud, et al / International Journal of Impact Engineering

for HVI and quite punctual for bullet impact) the input excitation is applied at a punctual location of the model, corresponding to a GRID point of the mesh.

- The solution is obtained with a modal transient response (SOL 112). This is an indirect solving of the transient response of the structure which means that modal analysis has been performed prior to solving transient excitation with modal basis.

The analysis have been made in free - free conditions (which means without interface clamping) representative of orbital conditions.

\subsection{Conclusions on Modeling}

Impact location: as multiple impacts have been made on the same target on different impact points located off centre along the horizontal median line of the target. The loading was thus applied at these different locations which introduces a certain degree of variability in the results that could lead to mode excitability modification (especially when the excitation is made at characteristic points such as panel middle). If HVI generated model loads are applied close to the symmetrical target center, first modes response are not coherent with test results. Symmetry may be perfect for FEM but it is not the case in reality and first modes can highly respond in tests configuration and be passive for modeling. As a consequence, simulations loads should not be applied too close to target symmetric point or axis to see the first measured modes appearing.

Modal truncation: the calculations are made through a transient modal response, which means that the shock induced transient response is calculated over the modal spectra. Calculation times are shorter than with respect to direct solving, nevertheless, the response is sensitive to the modal truncation, which means the frequency range on which the modal calculation is applied. The preliminary rules that could be set out to deal with modal truncation are the following:

- The modal truncation should be large enough to take into account the main frequency response of the structure and the frequency content of the excitation.

- The impacted part should be detailed enough to absorb the applied load frequency content. High frequency content is quickly subject to attenuation when transmitted to the rest of the structure through links. The main objective is to emphasize low frequency content transmission which consists in the main source of instability for spacecraft.

0 (a) emphasizes that for a given FEM and a given applied load, modal truncation has no effect on low frequency modal response.

Injected energy: the underlying physics behind HVI is the quantity of injected energy in the structure converted in mechanical load. HVI are associated to very short duration excitation and the influence of excitation duration keeping the same injected energy is studied in this section. The energy injected in the model is numerically calculated at impact location:

$$
E_{n}=\int_{0}^{t 0} F(t) \cdot V(t) \cdot d t
$$

To estimate representative aspect of this energy criterion, different excitation functions (with very different frequency contents) have been applied to the same target modeling (see $0(\mathrm{~b})$ ). The main conclusion drawn by the study: when analysis modal truncation is lower than main frequency content of the excitation (which is usually the case for spacecraft study where frequency truncation is lower than 
Vergniaud, et al / International Journal of Impact Engineering

$1 \mathrm{kHz}$ ), the shape and the main frequency content of the applied loads have relative reduced influences as far as the same energy is injected.
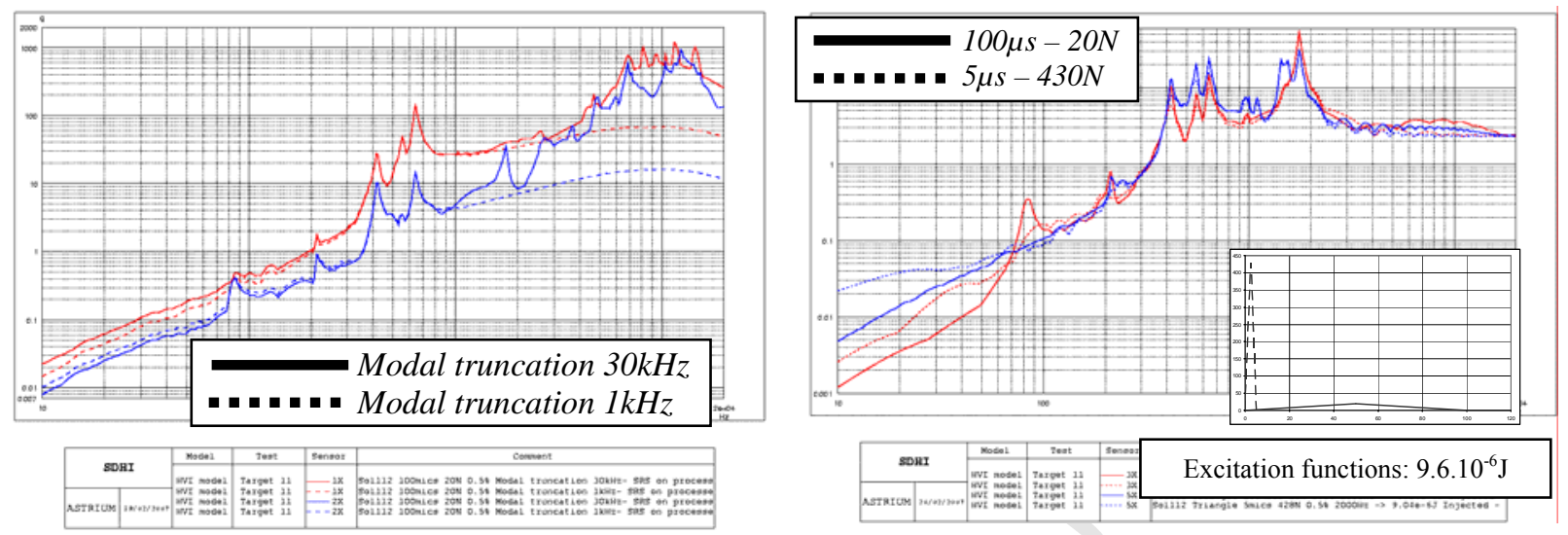

Fig. 6. (a) Effect of modal truncation on SRS response of target 11 modeling - (b)Effect of excitation function on Target 11 response as injected energy is kept

\subsection{Tested Targets Correlation}

The purpose of the correlation is to adjust FEM parameters to correlate as well as possible the test data measurements with the model simulations. The different parameters adjustable are in order of critical criterion: excitation shape, excitation level, links stiffness and links configuration. Materials characteristics are not considered as adjustable parameters: target constituting materials used for this study are clearly identified. The correlation is made in different stages to use with a maximum of efficiency the test data available.

- The first stage consists in characterizing the excitation function in terms of force introduced in the model.

- This excitation function is then adjusted to model (considering previous section conclusions) and correlated with test results on single panel targets. This preliminary adjustment provides corresponding frequency content and SRS coherent level distribution.

- Damping is introduced in the modeling as a modal damping applied on the frequency range. It is directly derivate from experimental results.

- Finally, correlation is made on assemblies with adjustment of links characteristics (stiffness and geometry).

\subsection{Extrapolation to Gaia Spacecraft}

\subsubsection{Extrapolation of excitation function}

The first step of this process final part is the empirical extrapolation of the excitation function to orbital impact conditions. This extrapolation is made on preliminary principle with estimation of velocity close to impact location (measured experimentally with laser velocimeter) and target displaced 
Vergniaud, et al / International Journal of Impact Engineering

mass due to HVI. Only the elastic wave is considered, the plastic wave effect, damped very quickly in the structure, is treated as elastic. The velocity of the impacted target is assumed to be equivalent to a pulse and approximated by polynomial-exponential decay function. This extrapolation is based on previous study (see [8] and [9]).

The objective is to have a realistic but preliminary estimation of the HVI equivalent force imposed at impact location. This extrapolation is thus made trough momentum quantity derivation of target displaced mass.

$$
F=m \frac{d V(t)}{d t}=m \frac{d}{d t}\left(A \cdot t^{2} \cdot e^{-\beta . t}\right)=m\left(2 A \cdot t \cdot e^{-\beta . t}-A \cdot t^{2} \cdot \beta \cdot e^{-\beta . t}\right)
$$

where $\mathrm{m}$ is the target mass displaced by impact and $\mathrm{V}(\mathrm{t})$ is target velocity extrapolated form test measurement and parameterized by $\mathrm{A}$ and $\beta$ coefficients.

The estimation of injected force is more complex when the impact location is made on composite material (sandwich panels) which is the case for Gaïa main walls and also for target sample used during test campaign. The fact that, depending on target impact conditions, projectile energy is mainly absorbed either by front sheet or by rear sheet of sandwich panel has to be taken into account.

For sandwich panels (Aluminum honeycomb $20 \mathrm{~mm}$ tick between two $0.5 \mathrm{~mm}$ thick CFRP face sheets), the front/rear sheet application force criteria is based on experiment and is determined by momentum quantity $\mathrm{Pp}$ of projectile. Above a momentum quantity limit, once significant penetration of the front face sheet has been achieved, the predominant degree of excitation occurs in the rear face sheet. This limit is determined by velocity measurement close to impact location. Increasing Pp when the velocity excitation peak starts to decrease, the rear face sheet in considered as the excitation face.

- If $\mathrm{P}_{\mathrm{p}}>1.82 \mathrm{~g} . \mathrm{m} / \mathrm{s}$, the force should be applied to rear sheet. In that case, the target displaced mass is equal to $\mathrm{m}=0.0597 .10^{-3} \mathrm{~kg}$ and velocity coefficients are equal to:

$$
A=13.01-3.839 P_{p}+0.378 P_{p}^{2} \quad \beta=1.0574-0.249 P_{p}+0.0247 P_{p}^{2}
$$

- If $\mathrm{P}_{\mathrm{p}}<1.82 \mathrm{~g} . \mathrm{m} / \mathrm{s}$, the force should be applied to front sheet. In that case, the target displaced mass is equal to $\mathrm{m}=0.0215 .10^{-3} \mathrm{~kg}$ and velocity coefficients are equal to:

$$
A=9.2667-0.14268 P_{p}+17.938 P_{p}{ }^{2} \quad \beta=2.903-1.486 P_{p}+0.798 P_{p}{ }^{2}
$$

$\mathrm{F}$ in this expressed in $\mathrm{N}$ when $\mathrm{Pp}$ is expressed in $\mathrm{g} . \mathrm{m} / \mathrm{s}$, $\mathrm{t}$ in $\mu$ s and displaced mass in $10^{6} \mathrm{~kg}$. The validity of this extrapolation is set to particles whose diameter is lower than $0.8 \mathrm{~mm}$. The fragmentation behavior with larger projectiles differs and does not allow realistic extrapolation.

For sandwich panels, the excitation function is extrapolated from the experiments (red curve on Fig. 7. $4 \mathrm{~mm}$ radius particle at $6 \mathrm{~km} / \mathrm{s}$, which represents an impact that statistically occurs once a year) to in-flight conditions which statistically occurs once a day on the overall structure of Gaïa (blue curve on Fig. 7. , 4.4.10 $0^{-6} \mathrm{~m}$ radius particle at $20 \mathrm{~km} / \mathrm{s}$ ). As in-flight impact conditions are very different from test conditions, it should be noticed that the extrapolation tends to be less precise for this range but remains an acceptable preliminary estimation.

\subsubsection{Gaïa Finite Element Model}

The second part consists in the application of the extrapolated loads on Gaïa FEM. The model used for HVI process application is the most updated FEM available considering project development: 
Vergniaud, et al / International Journal of Impact Engineering

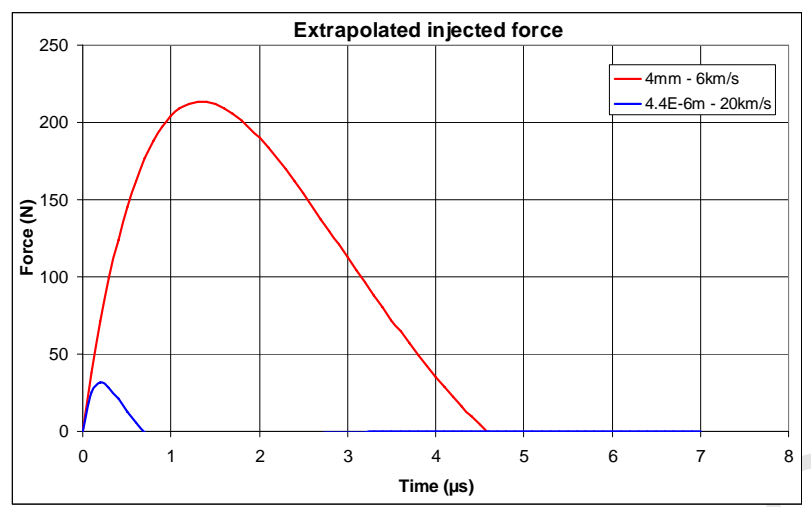

Fig. 7. Extrapolated force derived to in flight conditions

- The model of the platform structure (called service module structure: SVM) is the BRD model. This model does not contain sunshield model whose influence in orbital condition is assumed low on frequency range studied. The model is taken in empty tanks configuration.

- The model of the optical instrument containing optical bench (called Payload module: PLM) is the most updated SRR model which especially contains the line of sight angular variation calculation taking into account movement of every optical parts of the instrument (6 mirrors, focal plane, BAM and RVS). An overall view of the model is presented on Fig. 8. for instrument model detail.

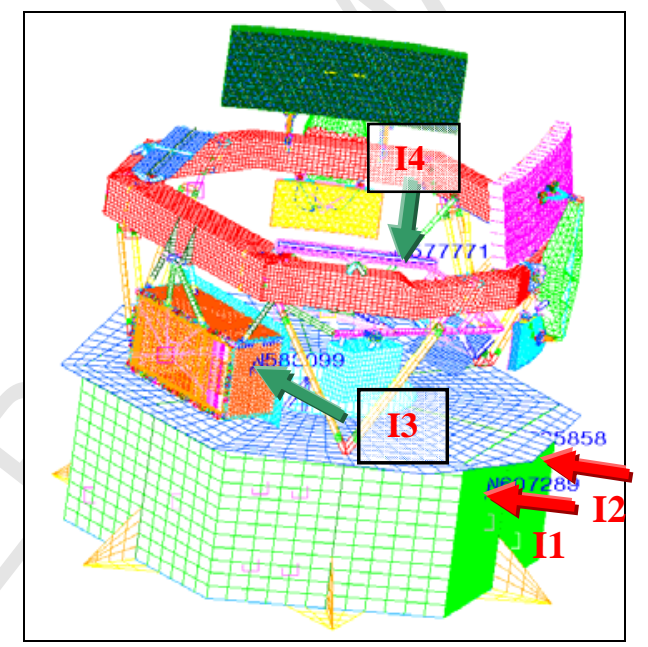

Fig. 8. Overall view of Gaïa FEM

The extrapolated forces described in section 4.4.1 are applied to four points of Gaïa finite elements model, two points on the service module and two points on the payload module (telescope) to have a complete preliminary estimation of line of sight deviation effect (see Fig. 8. ).

\subsubsection{HVI Criticality on Gaïa Performance}

The specifications of Gaïa performance are defined, for telescope line of sight angular variation, in 
Vergniaud, et al / International Journal of Impact Engineering

terms of RMS value on an acquisition time (RPE criteria) and in terms of frequency content evolution (AHFD criteria). These criteria are given by Gaïa project performance analysis and are specific to mission needs (see Table 3. ).

Table 3. Gaïa Line of Sight stability specification

\begin{tabular}{ccc}
\hline$R P E=3 \cdot \sqrt{\frac{1}{4.4} \int_{0}^{4.4} a(t)^{2} d t}$ & Along scan direction & Across scan direction \\
\hline$A H F D=\sqrt{\int_{1 / 10 T}^{\infty} P S D(f) \frac{1}{1+\left(\frac{1}{2 f \Delta t}\right)^{12}} \sin c^{2}(f T \pi) d f}$ & $\begin{array}{c}5 \text { milli-arc-second } \\
(\mathrm{mas})(3 \sigma) \text { over } 4.4 \mathrm{~s}\end{array}$ & $\begin{array}{c}10 \text { milli-arc-second } \\
(\mathrm{mas})(3 \sigma) \text { over } 4.4 \mathrm{~s}\end{array}$ \\
& $\begin{array}{c}3.4 \text { micro-arc-second } \\
(\mu \mathrm{as})\end{array}$ & $\begin{array}{c}100 \text { micro-arc-second } \\
(\mu \mathrm{us})\end{array}$ \\
\hline
\end{tabular}

For the four impacted points, line of sight deviation is calculated for daily event excitation and for yearly event excitation as defined in Fig. 7. . Results are presented in Table 4. for each performance criterion. It is important to notice that for the analysis, overall inertia momentum transfer to spacecraft is not taken into account. The spacecraft rigid movement induced by HVI has been subtracted for line of sight stability calculation. Only structural dynamic response is kept.

Table 4. Effects of daily and yearly extrapolated HVI force on Gaïa line of sight disturbance

\begin{tabular}{|c|c|c||c|c||}
\hline & \multicolumn{2}{|c||}{ Along scan direction } & Across scan direction \\
\cline { 5 - 5 } $\begin{array}{c}\text { Impact } \\
\text { locations }\end{array}$ & RPE (mas) & $\begin{array}{c}\text { AHFD } \\
(\mu \mathrm{as})\end{array}$ & RPE (mas) & $\begin{array}{c}\text { AHFD } \\
(\mu \mathrm{as})\end{array}$ \\
\hline I1 & 0.0070 & 0.0013 & 0.0519 & 0.0094 \\
\hline I2 & 0.0050 & 0.0014 & 0.0563 & 0.0135 \\
\hline I3 & 0.0247 & 0.0022 & 0.0716 & 0.0121 \\
\hline I4 & 0.1494 & 0.0089 & 0.2336 & 0.0395 \\
\hline \hline Spec & 5 & $\mathbf{3 . 4}$ & $\mathbf{1 0}$ & $\mathbf{1 0 0}$ \\
\hline \multicolumn{5}{|c}{ Daily Event }
\end{tabular}

\begin{tabular}{|c|c|c||c|c||}
\hline & \multicolumn{2}{|c||}{ Along scan direction } & \multicolumn{2}{c||}{ Across scan direction } \\
\hline $\begin{array}{c}\text { Impact } \\
\text { locations }\end{array}$ & RPE (mas) & $\begin{array}{c}\text { AHFD } \\
(\mu \mathrm{as})\end{array}$ & RPE (mas) & $\begin{array}{c}\text { AHFD } \\
(\mu \mathrm{as})\end{array}$ \\
\hline I1 & 1.2850 & $\mathbf{9 . 3 6 5 6}$ & 0.1853 & 1.3474 \\
\hline I2 & 0.8939 & $\mathbf{9 . 9 2 0 7}$ & 0.1824 & 1.8694 \\
\hline I3 & $\mathbf{2 7 . 6 3 2 8}$ & $\mathbf{7 8 . 6 8 4 8}$ & 2.3629 & 11.9528 \\
\hline I4 & $\mathbf{1 6 8 . 5 0 5 9}$ & $\mathbf{2 5 4 . 4 2 6 5}$ & $\mathbf{1 0 . 6 5 1 1}$ & 27.8976 \\
\hline \hline Spec & 5 & 3.4 & 10 \\
\hline \multicolumn{5}{|c||}{ Yearly event } \\
\hline
\end{tabular}

As it could have been expected, line of sight stability is all the more compromise as the impact occurs close to optical bench (I3 and I4 impacts induce more perturbation than I1 and I2 impacts). Nevertheless, impacts on SVM generate in test conditions levels of line of sight response which overpass AHFD specification. This means that even if impact occurs far from measurement part of the spacecraft (PLM), performance can be seriously affected. Propagation considerations can not justify this aspect as PLM and SVM parts are linked with interfaces which are sufficiently flexible to induce high damping of frequency content induced by HVI. The explanation is given by modal content of the structure which is stimulated by energy brought by impact. Overall spacecraft low frequency modes are responding inducing line of sight disturbance. On flight line of sight variations are associated to low displacement which mainly implies low damping factors (less than 1\%) and largely contributes to loss of stability performance. 
Vergniaud, et al / International Journal of Impact Engineering

The results show that Gaïa will not be disturbed by daily hyper velocity impact effect, but bigger particles (which statistically impact the spacecraft once a year and which are representative of impact conditions tested during this study) will potentially strongly disturb Gaïa line of sight stability. As a consequence, with these preliminary conclusions, mission should expect re-configuration need due to HVI events inducing loss of system performance.

\section{Conclusion}

This study allows validating the process of hypervelocity impact effect estimation on spacecraft dynamic stability. Test validation made on representative target (with respect to Gaïa structure) allows both a study of impact and target parameters effect on overall dynamic response of the structure and an extrapolation of the equivalent force introduced by the impact. Then, a theoretical study on material response to projectile enables the extrapolation of this impacted force to orbital conditions. This force is finally implemented on Gaïa finite elements model to give the estimation of line of sight disturbance induced by this type of impact. Line of sight response is compared to specification asked for this specific mission. The process has demonstrated that daily impacts will have in orbital conditions a very reduce influence on Gaïa performances. The stability specification will be exceeded for impacts similar to test conditions, which is corresponding to yearly event.

\section{Acknowledgements}

The authors are grateful for the support provided by Gaïa spacecraft project in ESA and ASTRIUM teams. They are also grateful for the support of French space national center CNES and CEG for having provided first preliminary test results on vibratory environment induced by HVI. This work has been performed as part of ESA Contract 18583 "Spacecraft Disturbances from Hypervelocity Impact".

\section{References}

[1] Schonberg WP. Hypervelocity impact response of spaced composite material structures. Int. J. Impact Engng., 1990; 10: 509-523.

[2] Schonberg WP, Yang F. Response of space structures to orbital debris particle impact. Int. J. Impact Engng., 1993; 14: 647-658.

[3] Albouys V, Loupias C. Essais au canon hypervitesse du C.E.G. - Mesure de chocs CNES. CNES-CEG R\&D, Réf. NT01-95/DTS/AE/MTE/3P, Issue 1, Rév 0

[4] Schäfer F. Spacecraft disturbance from hypervelocity impact - WP4000 - Impact testing. EMI Report, ESA contract 18583/04/NL/CH, 2007.

[5] Klinkart H, Walker R, Stockes H, et al. ESA Space Debris Mitigation Handbook, $2^{\text {nd }}$ Edition. ESTEC, Noordwijk, The Netherlands, 2002.

[6] Taylor AD. Earth encounter velocities for interplanetary meteoroids. Adv. Space Res., 1995; 17: 205-209.

[7] Lawrence RJ. "Enhanced Momentum Transfer from Hypervelocity Particle Impacts", Int. J. Impact Engng. 1990; 10: 337-349.

[8] Christiansen EL. Design and Performance Equations for Advanced Meteoroid and Debris Shields. Int. J. Impact Engng., 1993; 14: 145-156.

[9] Schäfer F, Haas S. Preliminary evaluation of critical impact conditions leading to failure. EMI Report No. I 50/04, Freiburg, Germany, July 14, 2004. 